\title{
Then and Now: Concluding Remarks
}

In the 1960s, health and social care authorities generally ignored research indicating that accurate psychiatric diagnosis and proper treatment, in hospital and in the community, could improve the well-being of older people and reduce the need for long-term institutional care. The research findings contradicted time-honoured teaching and widespread assumptions about decline rather than recovery in old age. Most of the medical profession lacked interest, the public rarely demanded improvements, and the government, which had other priorities and feared an insurmountable 'burden' of more older people living longer, did not allocate resources to meet needs. These factors contributed to poor-quality care and overcrowding in the psychiatric hospital back wards. The AEGIS (Aid for the Elderly in Government Institutions) campaign, led by Barbara Robb, brought the situation to the fore.

These concluding remarks draw together aspects of the AEGIS campaign and Barbara's work. They also touch on the significant role of women in the campaign, the last years of Barbara's life, and AEGIS's legacy for twenty-first century health and social care policy and practice.

\section{The AEGIS Campaign}

The AEGIS campaign developed in response to Barbara's and Strabolgi's anguish about the care Amy Gibbs received in Friern Hospital and dissatisfaction with official responses to their complaints. The Ministry could

(C) The Author(s) 2017

C. Hilton, Improving Psychiatric Care for Older People, Mental Health in Historical Perspective, DOI 10.1007/978-3-319-54813-5_8 
have dealt with many of their criticisms about standards of care early on, when it received the 'Diary of a Nobody' or after Barbara's meeting with Tooth, but a bureaucratic, defensive and self-justifying culture militated against this. The NHS administrative hierarchy was secretive, hostile to criticism, and sometimes deceitful, exemplified by the Friern Hospital Management Committee disregarding independent research about the adequacy of hospital staffing, the Regional Hospital Board (RHB) ignoring the Blofeld Report, and Kenneth Robinson announcing that Findings and Recommendations concluded 'very favourably' about standards of care provided.

During the AEGIS campaign, patterns emerged of disrespectful illtreatment towards older, chronically mentally ill and 'subnormal' people in long-stay hospital wards. Practices that patients, visitors and new staff perceived as cruel included slapping, teasing, rough handling, undignified bathing, lack of privacy and deprivation of personal possessions. Overcrowding and understaffing were associated with time saving, sometimes harsh, methods, which nurses perceived as legitimate. Unkind practices were also founded on out-of-date knowledge, and negative attitudes towards patients. Staff rarely intended harm.

Patterns also emerged about the author-witnesses and other whistleblowers. Most were new to the hospital, idealistic about the well-being of their patients, and lacked formal health service-related professional qualifications. Some who were new to nursing in middle age probably worked below their potential in terms of their personal and intellectual ability. The authorities did not address the issues that they raised and harassment by colleagues led some to resign.

Similar to the attitudes within the NHS, the Sans Everything committees of inquiry were hostile towards the author-witnesses, discrediting their evidence as false, unreliable or exaggerated. They based their perceptions on the witnesses' status and presumed character, rather than impartially evaluating the material presented to them. They grounded their decisions on standards set by the senior staff who they were judging, rather than on independent sources about clinical practice. Some ignored, or were unaware of, recent recommendations about NHS complaint management, and they lacked professional experience of investigating statutory bodies who neglected their responsibilities to the detriment of the public. Overall, their evaluation of the evidence was flawed. Their conclusions revealed their stereotypical assumptions about nurses, older people, mental illness and the excellence of the NHS. The Council on 
Tribunals and the events at Ely, Whittingham, Farleigh and South Ockendon highlighted many shortcomings of the Sans Everything inquiries, casting doubt on the conclusions drawn from them.

In the complex field of health service policy development, AEGIS was only part of the process, albeit a significant one. AEGIS contributed by identifying issues and suggesting answers, stirring up public and professional support, pressurising the government and persisting until it took action. Helped by the media and idealistic social-rights investigative journalists and editors, Barbara's frankness jolted the conscience of people who already knew about inadequacies on the back wards but had failed to take action and those to whom the revelations were new. Robinson and Hackett regarded the press as primarily aiming to improve the circulation of their newspapers, and Barbara as wanting to sell copies of Sans Everything. They disregarded the sincerity of AEGIS and its supporters, and ignored the sense of justice that motivated them. It is a credit to the media that they sustained their interest. This helped overcome the normal human tendency to disengage with unappealing and distressing subjects and helped maintain public, professional and political awareness at levels that could produce constructive debate about policy change.

Through its psychiatric advisors, Barton, Whitehead and Enoch, AEGIS fed into the process of developing proactive, non-custodial, comprehensive psychogeriatric services and the Royal College of Psychiatrists' Group for the Psychiatry of Old Age (GPOA). Psychogeriatricians introduced best clinical practice and continued to lobby NHS authorities to resource proactive and effective community and hospital mental health services for older people. AEGIS also advocated for improvements in longstay NHS hospitals more broadly, and thus contributed to establishing the Hospital Advisory Service, a NHS ombudsman and more effective complaints procedures. These encouraged the NHS to improve services, and promoted strategies to deal with criticism, including transparent and balanced investigations that could result in corrective action if necessary. AEGIS helped develop guidance to manage violence in hospitals and stimulated nurses to examine their practices and terms of employment. It also helped inspire voluntary organisations, such as the National Association for Mental Health (NAMH), to adopt less apologetic and more assertive campaigning roles.

In contrast to the dissonant relationship between Barbara and Robinson, Barbara and Crossman saw eye-to-eye about the need to make improvements. Crossman, assisted particularly by Abel-Smith, 
Baker and Howe, contributed to AEGIS achieving its objectives. Following up on Crossman's plans, Keith Joseph (1972, p. v) acknowledged that NHS acute physical illness hospitals previously had 'legitimate priority', but stated that the Department of Health and Social Security (DHSS) now intended to improve health services for people with chronic disorders. How far and how fast these proposals materialised, to provide effective services which met needs, merits further study.

AEGIS operated relentlessly from 1965 until 1974, and then modestly until Barbara's death two years later. AEGIS existed only because of Barbara, but she did not function in isolation. She did not try to create a large organisation, and there is no evidence that she or AEGIS trained a successor to take over her role. AEGIS remained small, elite and financially and organisationally independent. Independence ensured that Barbara could be forthright and publicly outspoken, more than academics, nurses, doctors, lawyers and politicians who might jeopardise their reputation and future livelihood by doing so. When Barbara Castle invited Barbara Robb to join the Central Health Services Council, an advisory body to the DHSS, Barbara Robb and the AEGIS advisors agreed that: "AEGIS functions best as a totally independent body, and has the best hope of being of service to the Secretaries of State and to the public by continuing in that capacity. ${ }^{1}$

\section{REFLECTIONS ON BARBARA}

Jung, White, Robinson and Crossman could not quite fathom Barbara out. Jung wrote 'She decidedly leaves you guessing'; White did not know quite how to 'deal with' her; 2 and Robinson and Crossman both described her as 'strange'. ${ }^{3}$ Journalist Anne Robinson said that politicians 'really didn't know the beast they were battling with. They totally underestimated her'. ${ }^{4}$ To a degree, she was the 'misunderstood genius' of Jung's 'intuitive introvert' personality type (Jung (1923) 1971, pp. 401-402). She was able to engage with people in all social classes and to treat them as partners in her campaign. Her psychotherapy skills helped them express their concerns and ideas, to which she paid the utmost attention. ${ }^{5}$ People who worked with Barbara, such as the author-witnesses, were intensely loyal to her. Barbara also had her faith, which was central to her life and work, ${ }^{6}$ and Brian (Fig. 8.1) supported her emotionally and helped practically with cooking and domestic tasks, enabling her to lead AEGIS (Allen 1967). 


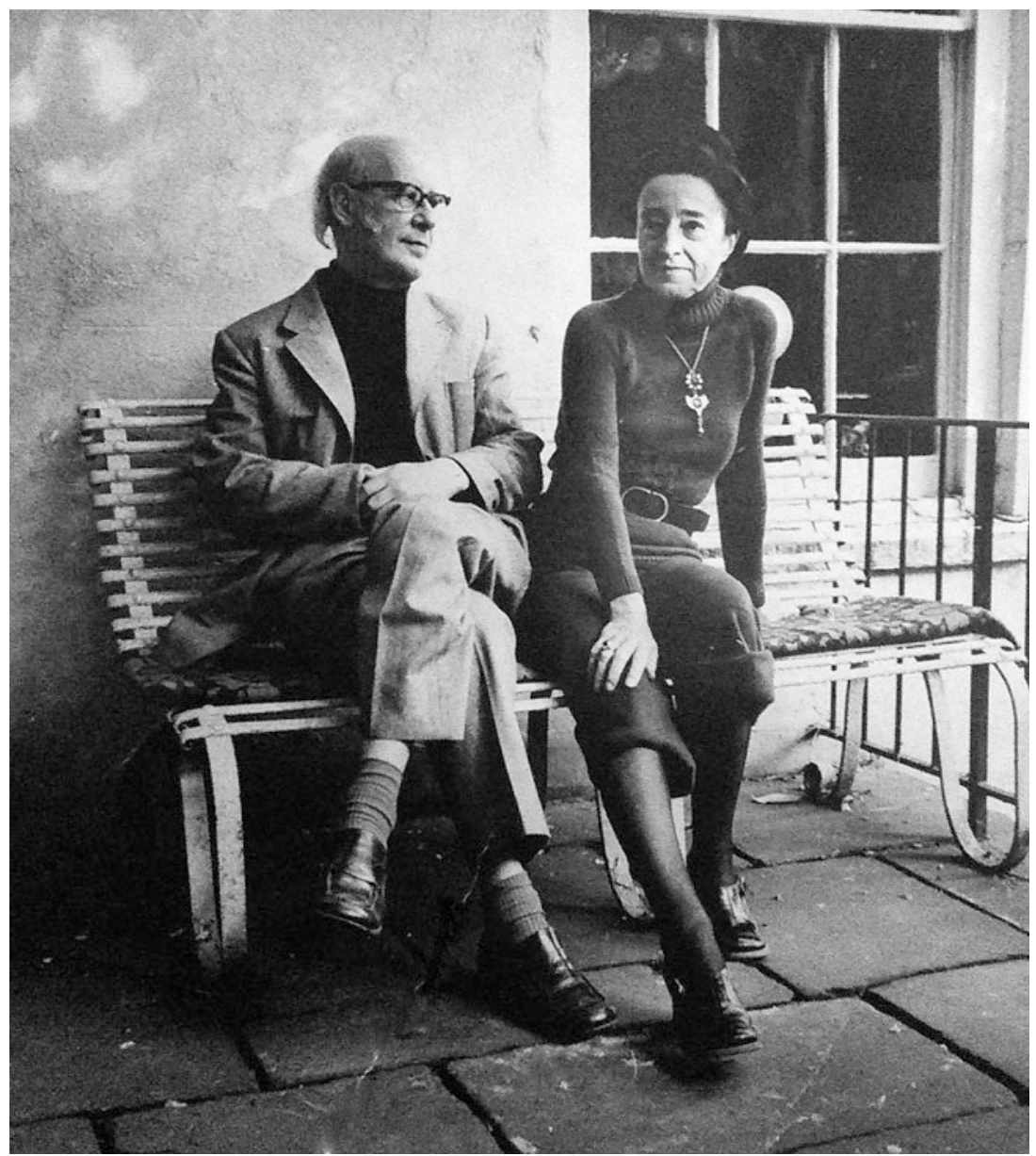

Fig. 8.1 Barbara and Brian Robb, c.1972. Reproduced courtesy of Elizabeth Ellison-Anne.

Harvey (1976) attributed Barbara's ability to command, and to work as an equal in elite ranks of society without feeling intimidated, to her upperclass background. She fought politically, went to the top and inspired individuals and organisations. She would not be thwarted by officialdom. Barbara's determination, self-confidence, skills and sense of justice 
antagonised the authorities who described her as a 'bloody nuisance' (Rolph 1987, p. 182). Barbara described her campaign style (Anon. 1976): 'I'm better suited to Walls of Jericho than to Trojan Horse tactics.' The Sunday Times described her extraordinary drive and her punishing schedule, twelve hours a day, six days a week, including acting as counsellor to 'hundreds of distressed nurses" ${ }^{7}$ and responding personally to a constant stream of correspondence. AEGIS's address list comprised 1,600 names by $1973 .^{8}$

Anne Allen (1967) compared Barbara to notable forebears, such as Lord Shaftsbury and Florence Nightingale: 'When everyone else accepted, as facts of life, women working down mines, parents having the right to beat their children, or soldiers dying for lack of good nursing, one person condemnedand won.' Unlike her forebears, public, political and personal factors contributed to Barbara being largely forgotten, despite the role she played in overcoming abusive practices and shaping health policy. Public and political factors included Robinson discrediting Sans Everything, the Ely Inquiry overshadowing it and Barbara being eclipsed by people more formally prominent, and career-wise determined to be so, within government and political circles. Personal factors included Barbara pursuing her campaign rather than personal recognition, her move to behind-the-scenes lobbying after 1970 and her and Brian's untimely deaths. Rolph discussed with Barbara her intention to write a book about AEGIS and Sans Everything, but there was no time to do so during her campaign, ${ }^{9}$ and her death, while still in the middle of her work, precluded it. Some people recognised Barbara's achievements in her lifetime. Strabolgi, in 1969, suggested 'an award of some kind' for her, and discussed this with Brian. Brian replied to Strabolgi that Barbara had refused two similar proposals and that she would not accept this one because 'the attainment of her objectives is so incomplete. ${ }^{10}$ Barbara Castle wrote to her in 1974: 'Dear Barbara,... You can feel proud at the outcome of all your efforts. Yours, Barbara." ${ }^{11}$ For all Barbara Robb's objectives to be moving towards fulfilment by the time she died was remarkable.

\section{Women AND THE AEGIS CAMPAign}

In the 1960s, the women's movement tended to focus on young women. Campaigning related mainly to employment, welfare rights, pay, taxation and women's control of childbearing (McCarthy 2010, pp. 109-110). It overlooked the needs of the oldest and most dependent women. It would require more research to be conclusive about whether sexism contributed 
to the neglect of older people on back wards, who were mainly women with no financial means, and underprovision of alternative community social support for them.

Among women of working age, relatively few walked the paths of power in government, in the health service or in journalism. Many who were idealistic, and had the means and the time, worked voluntarily for the betterment of society. Thus, in some ways, Barbara worked within the framework expected of her class and generation. Looking after people was considered women's work, and this probably reflected the forty or so women who contributed significantly to the AEGIS narrative. Some worked as volunteers, and others were paid, but the content of their jobs, either of their own choice or offered to them by employers, exemplified the traditional female caring role relocated to the public arena. Examples are Helen Hodgson, Mary Applebey, Ann Blofeld and Yvonne Cross. In the days when female journalists on national newspapers were rare, male editors would allocate them the health and welfare stories, in line with social expectations about their gender, a tacit sexism. At the Guardian, if 'they needed somebody to cover a bed-pan story ... where did their eyes go, you can do that Ann,' recollected Shearer. ${ }^{12}$ Thus three female journalists on national newspapers-Anne Allen, Anne Robinson and Ann Shearer-reported on psychiatric hospitals. Similar to Barbara and the Sans Everything witnesses (male and female), they experienced hostility, personal criticism and attempts by NHS authorities to intimidate them in the course of their reporting about Sans Everything, Harperbury and South Ockendon. ${ }^{13}$

Barbara's appearance was startling, as the men-folk discussed with emotional overtones and in ways that could have affected their working relationships with her. Jung described Barbara as 'an eyeful and beyond!' and White called her 'quite a corker'. ${ }^{14}$ Rolph described in his memoir asking Crossman whether Barbara impressed him: 'Impressed?' Crossman responded, 'Have you seen the hats she wears?' In Rolph's opinion (1987, p. 183): 'Even if it were possible to forget Barbara, it would not be possible to forget those extraordinary, carefully chosen, and obviously expensive hats, with which she seemed to transmute every occasion into a kind of one-woman Ascot.' Women also commented on Barbara's appearance and manner, but in ways that were more factual and related to her role. Anne Robinson described her appearance: 'immaculately dressed with the makeup and the hair.... with quite long black skirts, and a rather good cashmere roll neck sweater.... She was charming, and exotic in a way. ${ }^{15}$ Harvey (1976) commented that Barbara 'must have been the most elegant of hospital researchers, the most tender and 
the sharpest eyed'. Despite being 'tender', Barbara openly admitted that she could 'cut up rough' especially if she thought officials were obstructing her (Robb 1967, p. 83).

More overt than sex discrimination in the course of the AEGIS campaign, was arrogance from those in authority, bordering on bullying, related to designated status within the NHS hierarchy. Men and women who challenged higher tiers of staff in the hospitals, RHBs or the Ministry, were disparaged almost automatically. Although this was particularly common for staff without formal qualifications, seniority did not protect a critic. The authorities ostracised Barton, for example, despite being a male medical superintendent. Being a peer did not protect Strabolgi from Robinson reprimanding him for his speech in 1965, and a senior Home Office civil servant ominously challenged Rolph about his involvement with AEGIS without further explanation: 'Why are you signing letters for AEGIS? ... you've no idea the trouble there is going to be about that business. ${ }^{\text {, }}$

\section{After August 1974}

Barbara's page-to-a-day desk diary suddenly stopped in August 1974. A note sent to the telephone-diversion answering service that she usually used when on holiday read: 'Please explain that AEGIS is temporarily closed down but hopes to re-open in October, organised on a rather different basis. ${ }^{17}$ Her diary began to fill again at the beginning of November, but never regained its sense of busy-ness.

In the last few months of her life, Barbara began to sort her archive (Cochrane 1990, p. 26). At the end of her life Brian cared for her at home, with the help of a nurse (a black woman who was also an opera singer) and Henrietta Charlton, her niece and god-daughter. ${ }^{18}$ Barbara died on 21 June 1976, age sixty-four. A service took place at St Mary's Catholic Church, Hampstead. Barbara was cremated and her ashes were deposited in the Anne family cemetery at Burghwallis where a modest stone commemorates her. Her epitaph reads: 'Fearless champion of the cause of old people in hospitals.' An obituary appeared in the Hampstead and Highgate Express (Anon. 1976) and Harvey (1976) wrote one in the Times. She attributed Barbara's success to 'a mind free from academic restraints, to a gift for witty and trenchant expression, to upper class nerve, Yorkshire doggedness, an inbuilt Catholic faith, and above all, a near perfect marriage to Brian.' 
Brian wrote, illustrated and published two children's stories, My Grandmother's Djinn (1976) and The Last of the Centaurs (1979). Both are allegories about Barbara's work to rectify unethical situations. My Grandmother's Djinn is an adventure about the rescue of a single 'victim', a djinn or genie in a bottle, by 'Ursula' (Barbara) assisted by the narrator (Brian) and a small band of helpers. They faced challenges and obstacles demanding determination, kindness, insight and ingenuity, ultimately rescuing hundreds more djinns from imprisonment in bottles. The symbolism is clear: Barbara's work to rescue one person, Amy Gibbs, achieved much wider and lasting outcomes (Fig. 8.2). Illustrations of Ursula show her with two long dark plaits, as Barbara wore her hair in childhood (Figs. 8.3 and 8.4). In The Last of the Centaurs (1979) Barbara is represented by Ursula and Achilles, a centaur. Achilles, disguised as a horse, won the Epsom Derby in an escapade to support Ursula's impoverished uncle who had lost his job due to a boss who would not listen. Brian, as narrator, wrote:

It aroused in her mind a sequence of ideas that was eventually to carry the day. The first inklings of these came when one morning I saw her retire, with a bundle of newspapers, some paint and some paste, up into the attic. But I quite failed to guess their significance, and merely thought how odd it seemed for her to fritter away her time...

Later I was to feel ashamed to have so much misjudged her...

She had always been something of a loner...

For though the victory was due entirely to Achilles... I received an undeserved measure of praise, and must confess that I enjoyed my share of the glory.

Brian was devastated after Barbara died and then had to cope with his own disabling neurological disorder. ${ }^{19}$ Quentin Blake, who visited him in the institution where he was cared for, recalled that even when confused, his conversation was more interesting than most other people's most of the time. ${ }^{20}$ Brian died in 1979. His name shares Barbara's memorial stone at Burghwallis, with the epitaph 'A painter of distinction'.

\section{Relevance to Current Practice}

Since the 1960s, many positive changes have taken place in health and social care provision for mentally and physically unwell older people. Proactive treatment and rehabilitation services exist across the NHS. 


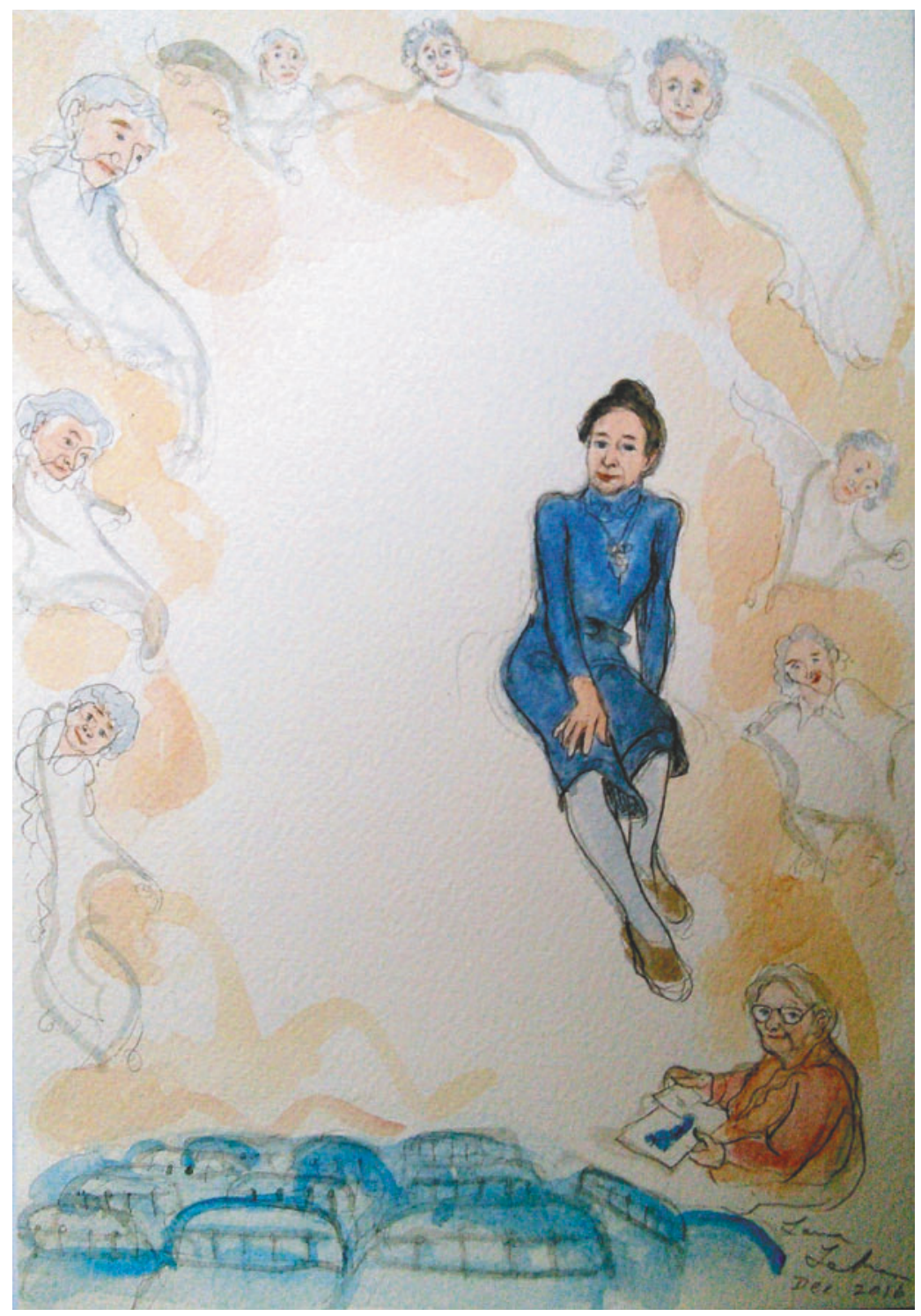

Fig. 8.2 'Older women, djinns and beds' by Laura Lehman, 2016, inspired by Ward F13, photographs of Barbara and Amy, and Brian Robb's illustrations. Ursula first rescued her grandmother's djinn and Barbara first rescued Amy. Both ultimately achieved much wider and lasting outcomes, freeing many more from overcrowded, custodial and undignified conditions. 


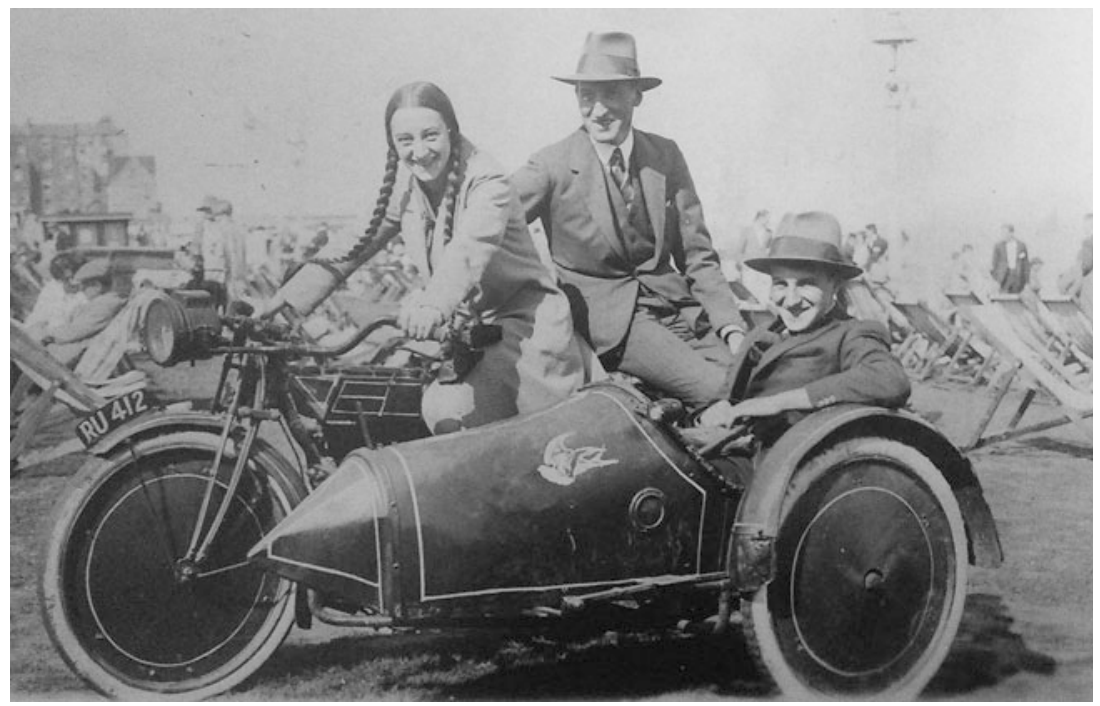

Fig. 8.3 Barbara in the driving seat: at the seaside with her father George and brother Michael, 1928. Reproduced courtesy of Elizabeth Ellison-Anne.

People who might have been resident in psychiatric hospital back wards in the 1960s today live either in their own homes, despite disability and frailty, or in a myriad of mainly privately run care homes. Standards of care still vary, from very bad to very good, whether in care homes, general hospitals or the person's own home. In Bergmann's view (2009, p. 62), 'if one wants to sum up the difference between the old psychiatric hospital scandals and nowadays it's sweeping it under one big carpet or hundreds of small rugs'. In terms of providing adequate NHS resources to create and run services, mental illness lags behind physical illness (Hilton 2016) and psychiatric services for older people lag behind those for younger people (Hilton 2012a, 2012b). Mental health provision for older people today aims to be evidence based, rehabilitative, dignified and humane, as AEGIS sought to achieve. The GPOA, now a Faculty, and its members throughout the NHS and beyond, collaborate with government bodies, local authorities, care homes, voluntary organisations and other health service disciplines, aiming to achieve high standards.

Angie Ash's (2014) study of scandals of care since 2010 found alarming similarities to Sans Everything, including ageist attitudes, underresourced 


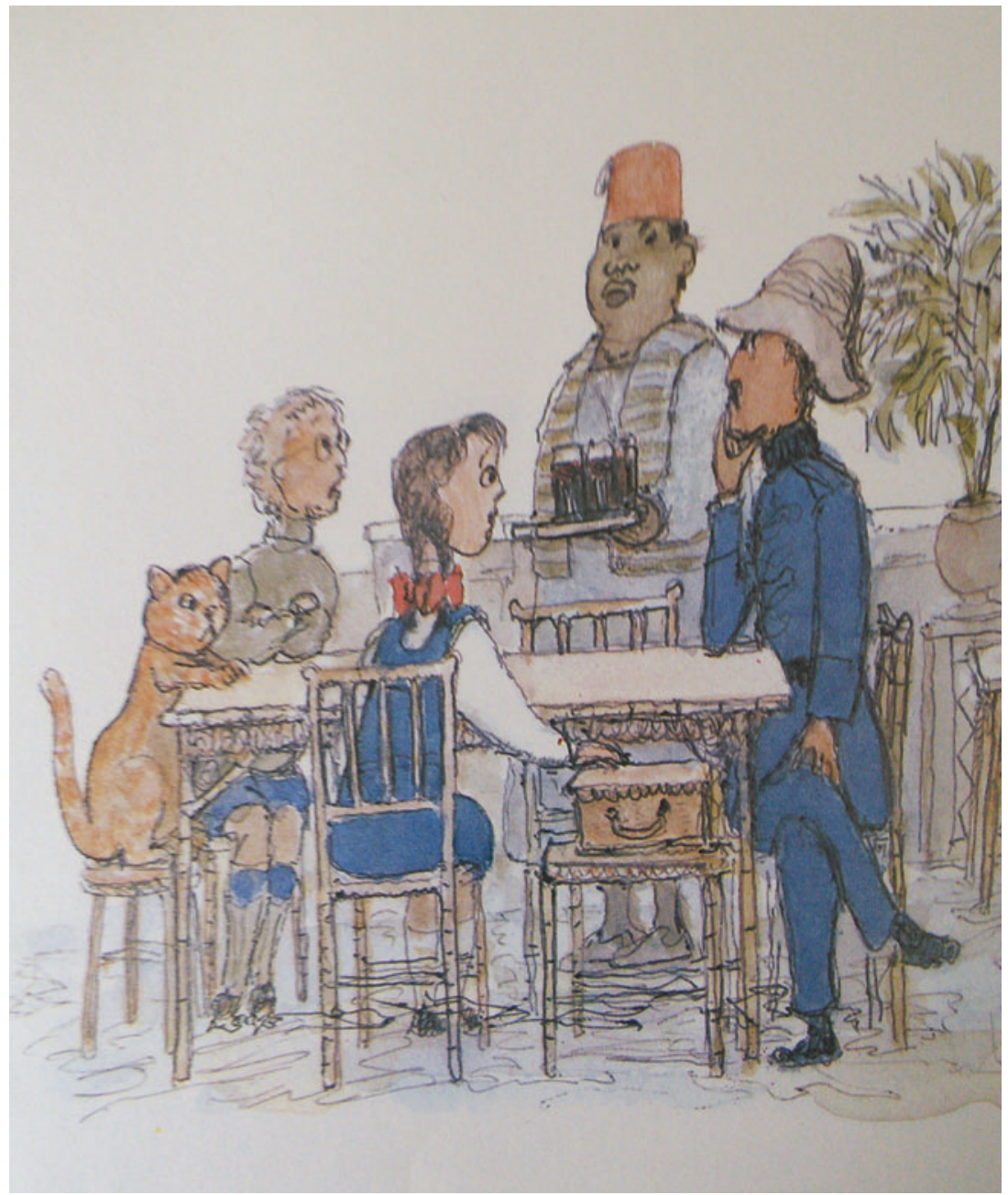

Fig. 8.4 'Ursula', with long plaits, by Brian Robb. Originally published in $M y$ Grandmother's Djinn (London: André Deutsch, 1976). Copyright: Carlton Books Ltd holds the rights for the book but was unable to ascertain if it holds the rights to the images. Presumed orphan work. 
and target-driven services, and organisational cultures of blame and scapegoating. Harsh treatment of whistle-blowers recurs, as does institutional secrecy about bad practice. Examples of these occurred at a hospital in Carlisle (1996-2000), a sequence of events uncomfortably reminiscent of the 1960s. An internal report identified low standards of care, including tying elderly patients to commodes, forcing them to eat while restrained, and staff washing their genitals with a flannel later used to clean their face. The report was concealed from the hospital's senior management. Student nurses who helped expose the abuse were disciplined and pilloried by staff, while some accused staff 'received a lot of support from colleagues', similar to the events at Farleigh Hospital. In Carlisle, the subsequent inquiry found 'degrading - even cruel-practices', vindicating the students (Herbert and Laurance 2000). The National NHS Staff Survey (2015) included three questions concerning 'unsafe' clinical practice: would staff know how to report concerns (86 percent answered yes), feel secure in raising them (70 percent 'agree' or 'strongly agree') and be confident that their organisation would address them ( 56 percent 'agree' or 'strongly agree')? Similar to the questions the Nursing Mirror asked its readership in 1967, the responses indicate that difficulties still exist for staff who observe, or who are expected to carry out, practices that disturb them. Victimisation of activists who criticise the NHS in the course of seeking improvement still happens. Local people accused Julie Bailey, a patient's relative who led the Stafford Hospital campaign 'Cure the NHS' (2007-2013), of lying and wanting to close the hospital rather than improve it, even after a public inquiry revealed gross failings (Anon. 2013, 2014). Similar to findings by AEGIS, the Parliamentary and Health Service Ombudsman (2015) reported that patients over sixty-five often did not know how to raise concerns or were too scared to complain about their care, fearing negative consequences. Chris Smyth (2015) reported in the Times that 'The NHS gets away with complacency because people are so grateful for their care.' In Barbara's time, undercover newspaper journalists worked in hospitals and exposed callous and harsh treatment. In 2014, covert television journalists revealed similar inhumanities (Panorama 2014).

Barton (1967, p. ix) stated that complaints and criticisms 'may cause management ... to embark on over cautious supervising'. Tighter monitoring and control is often employed in an attempt to raise standards, but it has drawbacks. In 1960s psychiatric hospitals rigid hierarchical management and strict obedience to seniors had damaging effects. Similar problems occur today when NHS staff are expected to conform to strict 
clinical protocols or 'care pathways'. Many pathways were created idealistically, but rigid interpretation means that they can become associated with unthinking, mechanistic practice that can detract from individual, person-centred care, demotivate staff and stifle creativity. Top-down monitoring means that it is difficult for staff to deviate from pathways deemed to be correct, even if they do not fit with an individual's care needs (Department of Health 2013). Thus some hospital and care home regimes are uncomfortably close to the mechanistic and task-driven care on the back wards in the 1960s, with accompanying risks of objectifying and dehumanising the person requiring care.

Other difficulties identified by AEGIS related to overcrowding and understaffing, problems that reemerge in modified forms. Today the NHS has fewer beds, associated with rapid throughput, with some patients being discharged before they are sufficiently well. This is less visible than excessive numbers of beds on a ward but is nevertheless a pernicious form of overcrowding, in time rather than in space. In particular, managers take pride in rapid patient throughput and may assume incorrectly that discharge indicates adequate and effective treatment in a shorter time, and therefore a lower financial cost. If staffing levels have not increased in line with the demands caused by shorter admissions, staff under pressure may work too fast for the patient's comfort, with insufficient time to give patients explanations for the care or treatment they require. Staff may inadvertently tolerate rough handling, undignified and untherapeutic care, and cause patients unnecessary distress. A report from the public services trades union UNISON $(2015$, p. 7$)$ commented on dangerously low ward staffing levels associated with management inaction, and it highlighted complacency about achieving satisfactory standards. UNISON stated: " $62 \%$ of respondents who had had a nursing "red-flag" [unsafe staffing level] event occur on their ward said that the ward was not immediately allocated additional staff.' Not only was the 'red-flag' unremedied, but managers' unresponsiveness linked to the risk of future underreporting of difficulties because staff lacked confidence that the process would achieve the desired outcome. This risks inadequacies being accepted as normal, irremediable or 'the best under the circumstances', linking to low standards, as happened in the psychiatric hospitals.

Today, most care homes are small, modern and well equipped, and facilities suggest that residents receive dignified care. As the scandals of Farleigh and South Ockendon demonstrated, the size and the modernity of the buildings did not relate to the standards within them. The physical 
environment in 2017 is usually good, but as Barton commented, there is the risk that superficial inspections assume that an obviously pleasant environment equates with good care. Recent investigations into small, modern homes have identified uncaring and dangerous practices, such as slapping residents, ignoring their calls for help and unsafe management of medication, hydration and nutrition (e.g., West Sussex 2014). On inspection days - in 2016 by the Care Quality Commission—staff are carefully briefed in advance and all is well prepared, as Barbara described at Friern and Davie at Storthes Hall. The pros and cons of announced and unannounced inspections merit further historical consideration to inform contemporary debate.

NHS hospitals today provide only short-term in-patient treatment and usually have active departments of geriatric medicine and 'mental health services for older people', (formerly psychogeriatrics). However, standards of care can still drop, as demonstrated by the Mid Staffordshire Inquiry (2013). Patients of all ages were affected at Stafford Hospital, but the report specifically mentioned older people, including that basic standards of care were not met: "No patient should be expected to tolerate the neglect and assault on their dignity that some were exposed to' (p. 1370). It recommended: 'Much of what needs to be done does not require additional financial resources, but changes in attitudes, culture, values and behaviour' (p. 1499). Recommendations since the 1960s for tackling inadequate care have been broadly similar: increasing staff levels, more training, improving supervision and inspection processes, and aiming to change institutional culture. These are important, and much has improved, although there is less evidence that fundamental attitudes have changed. In Martin's view (1984, p. 246), 'The bedrock on which the quality of care depends consists of staff and the ethics which motivate and guide them.' Tasks may be taught successfully through traditional practical training, but it is less easy to teach ethics, compassion or kindness in that way or to ensure that staff can effectively manage their emotional responses when stressed or when looking after behaviourally challenging patients. For staff to become more aware of their behaviours and responses, which they may regard uncomfortably as failings, requires thought, tact and reflection, not just knowledge of what ought to be done. This is important, especially for staff working with dependent, frail older people, confused due to delirium or dementia, who may unknowingly be irritating, repetitive, aggressive, ungrateful, demanding or physically 
unpleasant. If the older person's behaviours are interpreted as deliberate, staff are more likely to adopt punitive or demeaning ways of managing them, such as at Storthes Hall by the nurse who said he was treating rather than punishing a patient or at St Lawrence's when floor-cleaning soap was used to wash patients. Hands-on staff need the ability to recognise, and confidence to discuss, their negative and positive feelings towards patients. Senior staff need to listen and support. In conjunction with top-down approaches, more bottom-up opportunities for hands-on staff, in the form of discussion about ethics, morals, attitudinal and emotional aspects of workplace challenges, might help prevent unacceptable practices and recurrence of scandal.

It was apparent in Sans Everything that people new to the hospital and with minimal formal training often had the greatest insights into the humanity and quality of the care provided. Students may be particularly innovative, creative and idealistic, not yet having been conditioned to the views that their profession is meant to hold. The 'new eyes' effect is underutilised in the NHS. New staff are the least likely to be asked their views about standards of practice. It might be valuable if their feedback could be sought, preferably face to face, and if necessary by a member of staff in a different department, taking into account ongoing insecurities about criticising the authorities.

Barbara's work significantly influenced change for the better in hospital practice and NHS policy in the 1960s and 1970s, but inadequate care in the twenty-first century still requires rectifying. Recurrence of scandal does not invalidate the importance of her work, or that of other social reformers. Fry did not solve all the problems in prisons, nor Nightingale all those of nursing. Wilberforce and Shaftsbury would still have work to do today, such as dealing with modern slavery and people trafficking, exploited migrant workers, minimum wages and zero hours contracts. The nature of the difficulties in all these contexts centres round the imbalance of power between those in authority and others who are more vulnerable, for mental, physical, social, political or other reasons, thus risking exploitation, neglect or abuse. To a degree that had not been achieved previously, all the pioneers broke the chain of officialdom that overlooked or ignored inhumane practices. None of the pioneers provided all the answers, but each made crucial, pivotal contributions, consequently relieving much suffering and raising public awareness, with the potential to inform future eventualities. 
Barbara's grandfather Ernest told her as a child, 'when you see somebody needing help-help him', do not be a bystander to human suffering. Barbara illuminated the happenings on the back wards and broke through a conspiracy of silence about them. Her sense of justice, and her determination-Sans Varier - to make improvements, enthused many people during her lifetime, including doctors, nurses, journalists, academics, politicians and the author-witnesses. Her personal story is inspiring and lessons from her campaign remain pertinent. Fifty years since Sans Everything and forty years since Barbara died, it is rightful to recognise her place in history.

\section{Notes}

1. Letter, Robb to Hedley, 30 April 1974, AEGIS/1/10/D (AEGIS archive, London School of Economics).

2. Letters, Jung and White, 21 September and 7 October 1951 (in Lammers and Cunningham 2007).

3. Kenneth Robinson, interviewed by Margot Jeffreys, 1991 (British Library Sound Archive); Crossman Diaries, 16 March 1970, 166/70/SW 116-117 (University of Warwick Modern Records Centre, UWMRC).

4. Anne Robinson, interview by author, 2015 .

5. Tape recorded meetings, 11 May and 6 July 1971, AEGIS/4/27.

6. Mamie Charlton, letter, 2015.

7. Sunday Times, labelled 12 November 1972 (no title on archived cutting) AEGIS $/ 9 / 1$.

8. List of names and addresses, 1966-1973, AEGIS/9/13 and AEGIS/2/3.

9. Letter, Bill (Rolph) to Robb, l April 1968, AEGIS/B/3.

10. Letter, Brian Robb to Strabolgi, 29 October 1969, AEGISI/10/A.

11. Letter, Castle to Robb, May 1974, AEGIS/1/10/E.

12. Ann Shearer, interview by author, 2015 .

13. Anne Robinson, interview by author, 2015.

14. Letters, Jung and White, 21 September and 7 October 1951 (in Lammers and Cunningham 2007).

15. Anne Robinson, interview by author, 2015 .

16. Note by Robb, checked and approved by Rolph, 21 March 1974, AEGIS/ $1 / 10 / \mathrm{D}$.

17. Letter, Robb to Answering Ltd, 30 July 1974, AEGIS/9/3.

18. Letter, Mamie Charlton to author, 2015; Note, Henrietta (Hinny) Varley to author, 2016.

19. Elizabeth Ellison-Anne, discussion, 2016.

20. Quentin Blake, interview by author, 2016. 


\section{BIBLIOGRAPHY}

Allen, Anne. 1967. 'One woman who refused to pass by..'. Sunday Mirror, 9 July. Anon. 1976. 'The patients' campaigner'. Hampstead and Highgate Express, 25 June.

Anon. 2013. 'Stafford Hospital campaigner Julie Bailey to leave "hostile” town'. $B B C$ News, 6 June.

Anon. 2014. 'Julie Bailey: NHS campaigner suffers online abuse'. BBC News, 2 January.

Ash, Angie. 2014. Safeguarding Older People from Abuse: Critical Contexts to Policy and Practice. Bristol: Policy Press.

Barton, Russell. 1967. 'Foreword' ix-xi. In Robb 1967.

Bergmann, Klaus. 2009. In The Development of Old Age Psychiatry in Britain 1960-1989, (Guthrie Trust Witness Seminar 2008) ed. Claire Hilton. University of Glasgow. http://www.gla.ac.uk, accessed 18 September 2016.

Cochrane, David. 1990. 'The AEGIS campaign to improve standards of care in mental hospitals: A case study of the process of social policy change'. $\mathrm{PhD}$ thesis, University of London. http://etheses.lse.ac.uk, accessed 17 September 2016.

Department of Health. 2013. More Care, Less Pathway: A Review of the Liverpool Care Pathway. https://www.gov.uk, accessed 14 April 2016.

Hackett, Maurice. 1968. 'Ill informed, ill considered, and unkind'. Guardian, 14 December.

Harvey, Audrey. 1976. 'Mrs Barbara Robb', Times, 28 June.

Herbert, Ian and Laurance, Jeremy. 2000. 'Trainee nurses blew the whistle on abuse of elderly patients', Independent, 15 November.

Hilton, Claire. 2012a. 'Sans teeth, sans eyes, sans taste, sans everything: resourcing mental health services for older people, a long term view'. Journal of the Royal Society of Medicine, 105, 146-150.

Hilton, Claire. 2012b. 'No scope for complacency: observations on the guidance from the Royal College of Psychiatrists on the Equality Act and achieving nondiscriminatory, age-appropriate services', BJPsych Bulletin, 36, 441-443.

Hilton, Claire. 2016. 'Parity of esteem for mental and physical health care in the United Kingdom: a hundred years war?' Journal of the Royal Society of Medicine, 109, 133-137.

Joseph, Keith. 'Foreword' v-vii. In DHSS 1972. National Health Service Reorganisation. England. Cmnd. 5055. London: HMSO.

Jung, Carl. (1923) 1971. Psychological Types. (translation: H Godwyn Baynes, revised by RFC Hull). New York: Pantheon Books.

Lammers, Ann and Cunningham, Adrian, eds. 2007. The Jung-White Letters. London: Routledge.

Martin, John (and Evans, Debbie). 1984. Hospitals in Trouble. Oxford: Blackwell. 
McCarthy, Helen. 2010. 'Gender equality' 105-123. In Unequal Britain, ed. Pat Thane, London: Continuum.

Mid Staffordshire NHS Foundation Trust. 2013. Mid Staffordshire NHS Foundation Trust Public Inquiry HC. 947 (Francis Report) London: TSO.

National NHS Staff Survey Co-ordination Centre. 2015. NHS Staff Survey. http://www.nhsstaffsurveys.com, accessed 16 March 2016.

Panorama. 2014. Behind Closed Doors: Elderly Care Exposed, BBCl, 30 April.

Parliamentary and Health Service Ombudsman. 2015. Breaking Down the Barriers. http://www.ombudsman.org.uk, accessed 10 October 2016.

Robb, Barbara. 1967. Sans Everything: A Case to Answer. London: Nelson.

Robb, Brian. 1976. My Grandmother's Djinn. London: André Deutsch.

Robb, Brian. 1979. The Last of the Centaurs. London: André Deutsch.

Rolph, Cecil. 1987. Further Particulars. Oxford: OUP.

Smyth, Chris. 2015. 'Grateful patients unwilling to expose NHS failings'. Times, 21 December.

UNISON. 2015. UNISON's Staffing Level Survey 2015: Red Alert: Unsafe Staffing Levels Rising. London: Unison.

West Sussex Adult Safeguarding Board. 2014. Orchid View Serious Case Review. http://www.westsussex.gov.uk, accessed 17 September 2016.

Open Access This chapter is licensed under the terms of the Creative Commons Attribution 4.0 International License (http://creativecommons.org/licenses/ by $/ 4.0 /$ ), which permits use, sharing, adaptation, distribution and reproduction in any medium or format, as long as you give appropriate credit to the original author(s) and the source, provide a link to the Creative Commons license and indicate if changes were made.

The images or other third party material in this chapter are included in the book's Creative Commons license, unless indicated otherwise in a credit line to the material. If material is not included in the book's Creative Commons license and your intended use is not permitted by statutory regulation or exceeds the permitted use, you will need to obtain permission directly from the copyright holder.



